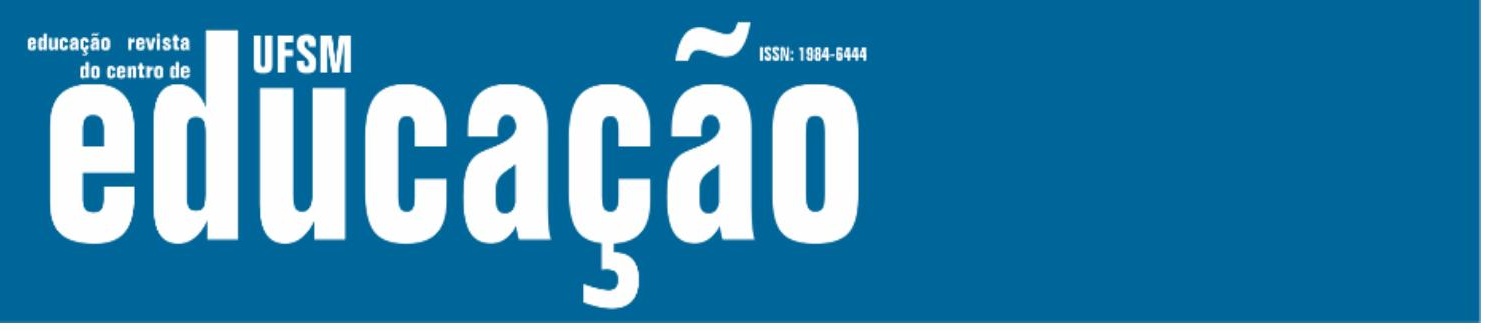

ISSN: 1984-6444 | http://dx.doi.org/10.5902/1984644442506

\title{
Pensamento pedagógico-geográfico de professor e a autonomia docente
}

\author{
Pedagogical-geographical thinking of teacher and autonomy teaching
}

\author{
Carina Copatti \\ Universidade Federal da Fronteira Sul. Chapecó, Rio Grande do Sul, Brasil. \\ c.copatti@hotmail.com - https://orcid.org/0000-0003-0485-388X
}

Recebido em 13 de fevereiro de 2020

Aprovado em 23 de agosto de 2021

Publicado em 30 de setembro de 2021

\section{RESUMO}

O artigo apresenta como proposta debater o conceito de pensamento pedagógicogeográfico de professor como constructo do profissional necessário à autonomia docente. Parte-se da seguinte questão: de que maneira, na formação do professor de Geografia, o Pensamento Pedagógico-Geográfico é constituído e como contribui à autonomia docente? Este artigo resulta de um recorte da tese de doutorado e propõe um debate teórico que relaciona referenciais teóricos e elementos originados da pesquisa empírica realizada com professores que atuam na educação básica, anos finais do ensino fundamental. Utilizou-se a entrevista semiestruturada como recurso e a Análise de Conteúdo de Laurence Bardin (2011) como metodologia de análise dos dados para a construção das categorias, as quais foram interpretadas a partir da Teoria Crítica e da Hermenêutica. Resulta, nesse processo, um movimento inicial de reflexão sobre pensamento geográfico e pensamento geográfico de professor e, posteriormente, reflexões sobre o conceito de Pensamento PedagógicoGeográfico como uma estrutura necessária à construção da autonomia docente do professor de Geografia.

Palavras-chave: Formação de professores; Autonomia docente; Pensamento Pedagógico-Geográfico.

\section{ABSTRACT}

The article presents as a proposal to debate the concept of pedagogical-geographic thinking of teachers as a construct of the professional necessary for teaching autonomy. It starts with the following question: in what way, in the formation of the Geography teacher, is Pedagogical-Geographic Thinking constituted and how does it contribute to teaching autonomy? This article results from an excerpt of the doctoral thesis and proposes a theoretical debate that relates theoretical references and elements originated from the empirical research carried out with teachers who work 


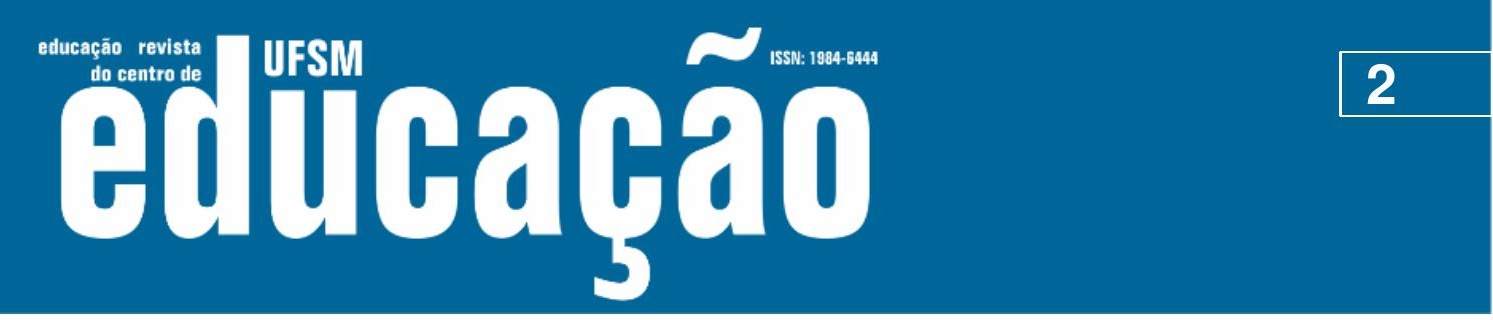

ISSN: 1984-6444 | http://dx.doi.org/10.5902/1984644442506

in basic education, the final years of elementary school. The semi-structured interview was used as a resource and the Content Analysis by Laurence Bardin (2011) as a methodology for data analysis for the construction of the categories, which were interpreted from the Critical Theory and Hermeneutics. In this process, an initial movement of reflection on geographic thinking and geographic thinking of the teacher results, and, later, reflections on the concept of pedagogical-geographic thinking as a necessary structure for the construction of the teaching autonomy of the Geography teacher.

Keywords: Teacher training; Teaching autonomy; Pedagogical-geographical thinking.

\section{Introdução}

Utilizar a linguagem como interlocutora de diálogos e para compreender estruturas de pensamento foi um movimento construído nos percursos que constituem as proposições trazidas ao debate neste artigo, o qual é originário de um recorte da tese de doutorado, defendida em 2019. A partir da pesquisa desenvolvida foi possível tecer interpretações e construir significações por meio da comunicação com professores que atuam na educação básica.

Estas reflexões potencializam o debate sobre a dimensão de formação em Geografia e os aportes necessários para a docência em âmbito escolar, finalidade principal da formação de professores nessa área do conhecimento. Nesse sentido, o debate centra-se na construção de elementos basilares a esse processo, o qual entende-se como um modo de pensar geográfico que pressupõe um modo de abordar a Geografia no contexto do ensino escolar, a partir do que denominamos de Pensamento Pedagógico-Geográfico (PPG).

Nesse debate, a questão central intenta responder: de que maneira, na formação do professor de Geografia, o Pensamento Pedagógico-Geográfico é constituído e como contribui para a autonomia docente? O objetivo, a partir dessa questão problematizadora, é debater o conceito de Pensamento PedagógicoGeográfico, compreendido como constructo do profissional, um processo necessário ao desenvolvimento da autonomia do professor para a docência. 


\section{T usm

ISSN: 1984-6444 | http://dx.doi.org/10.5902/1984644442506

raciocínio geográfico, relacionando-se a partir de determinados parâmetros - modos de compreensão - que serviram para a interpretação do espaço e das interações que nele são vivenciadas. Estes aspectos, relacionados entre si e abrangendo o modo de interpretação de cada autor, contribuíram para formar o arcabouço teóricoconceitual que constitui a Geografia. (COPATTI, 2019).

Figura 1 - llustração dos elementos que constituem o pensamento geográfico

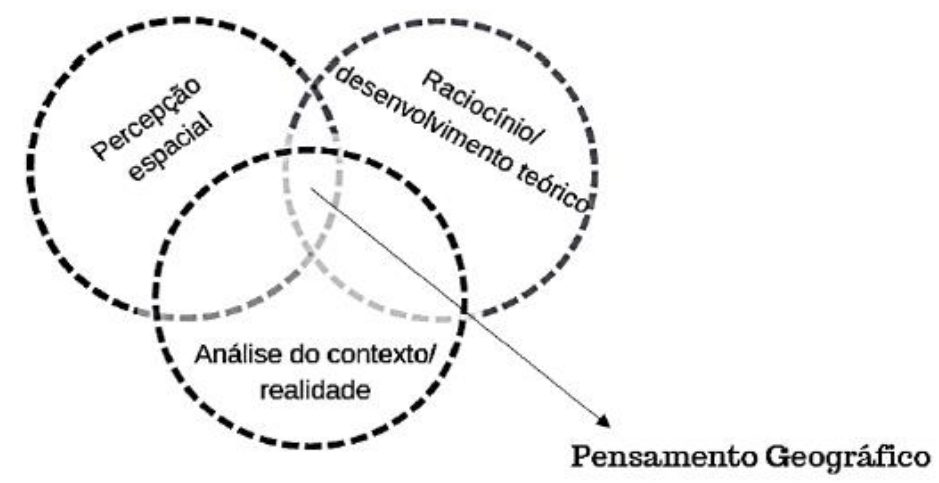

Fonte: Copatti, 2019.

A percepção espacial refere-se à interação com o espaço, que requer que se possa questioná-lo, problematizá-lo e, com ele, interagir de modo consciente. Com base em Sturza (2005), entende-se que a percepção é um processo dialético que envolve sujeito (homem) e objeto (lugar), considerando as relações/interações entre ambos e as interfaces objetivas e subjetivas, expressas ou obscurecidas, entre a dimensão da totalidade e as individualidades. Nesse constructo são consideradas vivências, memórias e percepções de grupos e indivíduos que contribuem para a construção de saberes geográficos permeados pelo imaginário social na interpretação do espaço geográficos. A análise do contexto e da realidade implica relacionar as dimensões do espaço e suas multiescalaridades a partir do processo de constituição espaço-temporal. O raciocínio/desenvolvimento teórico se refere à dimensão que aproxima a percepção espacial e a análise do contexto sob um viés de pensamento teoricamente fundamentado, que foi sendo construído ao longo do 


\section{Tism oltibapá

ISSN: 1984-6444 | http://dx.doi.org/10.5902/1984644442506

\section{Definição do pensamento geográfico pelos professores participantes}

Os fragmentos contendo ideias oriundas de cada professor são apresentados e inseridos no texto na ordem das entrevistas realizadas.

A professora denominada como Pt1 salienta que o pensamento geográfico vai além da sala de aula. Possibilita ao professor refletir sobre o mundo e analisar criticamente as mudanças, positivas ou não, naturais ou antrópicas. Segundo ela, "é um pensamento que possibilita olhar o meio com carinho e preocupação, que me torna cidadão ativo no mundo e não apenas um espectador".

O professor denominado Pt2 comenta que são dois os aspectos essenciais na construção do pensamento: a) a construção acadêmica que se dá no início da faculdade com o conhecimento dos conceitos e com a observação, e que é natural em qualquer ciência. b) Conhecimento de senso comum, que está no instinto, porque "Você aprende a se localizar: instinto primitivo: a localização, isso é um fazer geográfico".

A professora P1 não respondeu a esta questão. A professora $\mathrm{P} 2$, compreende o pensamento geográfico como "aquilo que os professores aplicam na interpretação dos fatos. A forma como analisam o meio parte do pensamento geográfico, pois leva em consideração as vivências, crenças e como encaram a cidadania".

A professora P3 considera que pensamento geográfico é "pensar a Geografia, como ela se caracteriza em cada momento. Evolução pensada e construída ao longo do tempo". E compreende que existem diferentes períodos históricos relacionados com a Geografia. Assim, leva em conta a evolução do pensamento, como foi pensado em cada fase e como o ser humano construiu e usou a Geografia em cada momento histórico, desde que ela foi reconhecida como uma ciência. Salienta ainda que o pensamento geográfico:

É ver a forma como se faz o conhecimento geográfico em cada época. Precisa das diferentes escolas da Geografia para explicar as demais. Então ela foi mudando e conseguimos ver o pensamento geográfico em diferentes momentos, de diferentes formas. 


\section{$\sim$

ISSN: 1984-6444 | http://dx.doi.org/10.5902/1984644442506

A professora $\mathrm{P} 4$ entende que o pensamento geográfico:

É construído a partir da leitura da parte teórica, associada com a prática. É isso que dá embasamento para fazer análises. O que contribui é a leitura acadêmica, a leitura fora da academia, a leitura no geral, inclusive acadêmica como base. E aí outra, às vezes estudando também o próprio material didático que a gente recebe, associando ao acadêmico.

O professor P5 interpreta pensamento geográfico pela linha da Geografia enquanto ciência, como que ela foi evoluindo a partir do determinismo, o possibilismo, a Geografia crítica, mais recentemente:

É saber como que ela foi se modificando, deixando de ser uma mera descrição e tentando inserir sempre o homem. Atrelando o homem e as relações sociais, o avanço das interpretações na relação com a natureza. É o estudo da própria Geografia.

A professora P6 entende que o pensamento geográfico:

É trabalhado desde o início da graduação, quando começam estudos da Geografia física, de olhar para essa questão das paisagens, da mudança delas, da interferência, a ideia da relação sociedade-natureza que ao longo do tempo vai sendo construída, primeiro na exploração dos recursos naturais depois de outras formas de ocupação, das mudanças ao longo do tempo em diferentes espaços, entendendo o objeto de estudo, o conceito.

E considera que a Geografia é muito complexa, pois "vemos tudo, mas nada tão aprofundado, mas vai muito além do que outras áreas veem". Segundo ela, a Geografia estuda o espaço geográfico, não o espaço pelo espaço, mas o estudo pelas relações, como isso se organizou, como processo, até a forma atual, a realidade.

A professora P7 interpreta o pensamento geográfico como aquele pensamento que não é só da academia: 


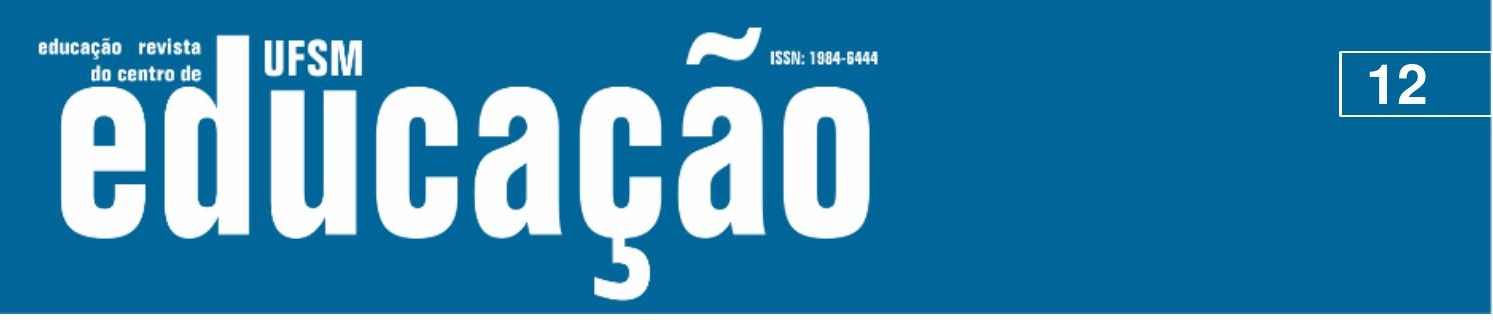

ISSN: 1984-6444 | http://dx.doi.org/10.5902/1984644442506

Você faz uma leitura do espaço, e pode ser tanto numa pessoa que nunca estudou Geografia, que tem uma visão espacial. Então é um pensamento, todo mundo pensa alguma coisa porque está no espaço. $O$ pensamento geográfico também é o pensamento das pessoas sobre o espaço no seu cotidiano. E aí então a pessoa tem um saber geográfico e o professor de Geografia também tem. Todo mundo vai ter um pensamento geográfico, mas alguns são mais validados do que outros. Não é só a academia, mas ela também contribui.

E a professora P8 entende que o pensamento geográfico é fundamentalmente construído a partir das disciplinas da graduação, com uma compartimentação que permanece e aparece muito na divisão e subcategorização da Geografia:

O pensamento geográfico é uma capacidade de ver o mundo a partir de determinados conhecimentos. Talvez pensamento geográfico não seja o ensino em si de Geografia, existem em uma quantidade de conhecimentos que podem me levar à Geografia, porque o pensamento geográfico é muito mais amplo do que a Geografia que conhecemos enquanto ciência. $O$ pensamento geográfico vem há muito mais tempo do que a Geografia científica, é maior do que a própria Geografia institucionalizada.

As ideias apresentadas pelos professores contribuem para que se possa lançar um olhar cuidadoso sobre os distintos aspectos que envolvem a construção do pensamento geográfico. Além destes, outros aspectos aparecem ao identificar especificidades do pensamento geográfico de professor, os quais são mencionados a seguir.

\section{Definição de pensamento geográfico de professor}

A compreensão dos docentes sobre o pensamento geográfico de professor é apresentada nos fragmentos das falas transcritas de cada participante.

A professora Pt1 afirma que o pensamento geográfico de professor se baseia na construção de valores e na formação acadêmica. Salienta que a construção de uma percepção crítica, a partir da Geografia crítica, que contesta a ação do homem sobre o seu meio, foi importante nesse processo de constituição do seu pensamento. E salienta que alguns professores traziam essa visão. Também leva em conta o contexto familiar como essencial nesse processo. 


\section{N-Tis

ISSN: 1984-6444 | http://dx.doi.org/10.5902/1984644442506

Para o professor Pt2, a construção do pensamento vai se aprimorando com o tempo. E explica: "Eu tenho dois contatos: é o contato de vida com o lugar e o meu contato com a ciência geográfica do cotidiano da escola, o meu olhar clínico sobre assuntos de política, de assuntos que caibam na Geografia".

Para a professora P1, a construção do pensamento geográfico de professor ocorre em um processo. A mesma considera, para isso, a formação inicial, a formação continuada e a relação com a vivência, com a realidade em que atua.

A professora P2 interpreta que existe um pensamento geográfico de professor e ele é mais complexo que a visão que o estudante vai ter do meio. Para a entrevistada "o professor não é um ser neutro, e nem existe neutralidade, porque somos resultado de experiências. Então, cada professor tem sua própria forma de analisar os fatos, a partir daquilo que aprendeu, vivenciou e vivencia na sua trajetória acadêmica".

A professora P3 afirma, sobre o pensamento geográfico de professor, que:

Na prática você não fica fazendo separação [referindo-se às perspectivas de pensamento geográfico], mas quando prepara um material de aula é muito nítido isso; de alguma forma utiliza essas escolas, e vê como se relacionam. Mas não é uma coisa explícita para o aluno. Está no material que você está trabalhando, te dá a base.

A professora P4 entende que o pensamento geográfico do professor auxilia a compreender a interação entre o ser humano e a natureza. "Está na lógica de buscar entender o que o ser humano faz no ambiente onde ele vive, no espaço natural, como interage. A partir dessa interação constrói o pensamento geográfico".

O professor P5 interpreta que:

O professor tem um pensamento geográfico, embora não determine, não se especifica os elementos, não denomina como pensamento geográfico. Não é como uma disciplina na graduação (exemplo: história do pensamento geográfico), que a gente tem na formação. [...] não falamos do histórico, mas inserimos elementos de modo diluído na sala de aula através do que os alunos vivenciam. 


\title{
$\sim$

ISSN: 1984-6444 | http://dx.doi.org/10.5902/1984644442506

Dessa forma, entende que o professor, considerando isso e a realidade, vai delineando esses conhecimentos, construindo conceitos que estariam dentro do pensamento geográfico (paisagem, natureza, território, lugar), inserindo nas necessidades de cada conteúdo. E vai, ao longo das aulas, diluindo aos poucos, de modo crítico esse conhecimento. Afirma ainda que:

O que contribuiu para fazer isso foram os professores, que contribuíram na formação do pensamento de professor, o trabalho de pesquisa, produzindo, desde a iniciação científica as leituras fundamentais, principalmente na graduação, e a experiência de sala de aula, que vai ajudando a aprimorar, reconstruir.

A professora P6 considera que a Geografia nos proporciona um olhar amplo perante a sociedade para ver como essas relações acontecem, desde o meio natural até os aspectos inerentes aos processos de transformação e relacionadas às causas e consequências dessas relações. Isso foi sendo construído ao longo do tempo dentro da graduação, nos trabalhos de campo, não só em sala de aula, pela teoria, mas também relacionando com a realidade.

A professora P7 considera o pensamento geográfico:

\begin{abstract}
Um conjunto de coisas, pelas trocas com outras pessoas ao longo do trabalho, da formação, na família, com os orientadores, das coisas que a gente escuta dos alunos, do que dizem ou não dizem para nós, das coisas que lemos de outras áreas, sobre um espaço distante, nos filmes de outros países, das artes, da poesia, do cinema, da literatura que aproximam de realidades mais distantes.
\end{abstract}

A professora P8 salienta que existem vários conhecimentos importantes, os quais podem tornar possível chegar a determinadas conclusões a partir do pensar e sobre pensar o que é o pensamento geográfico. Segundo ela: 


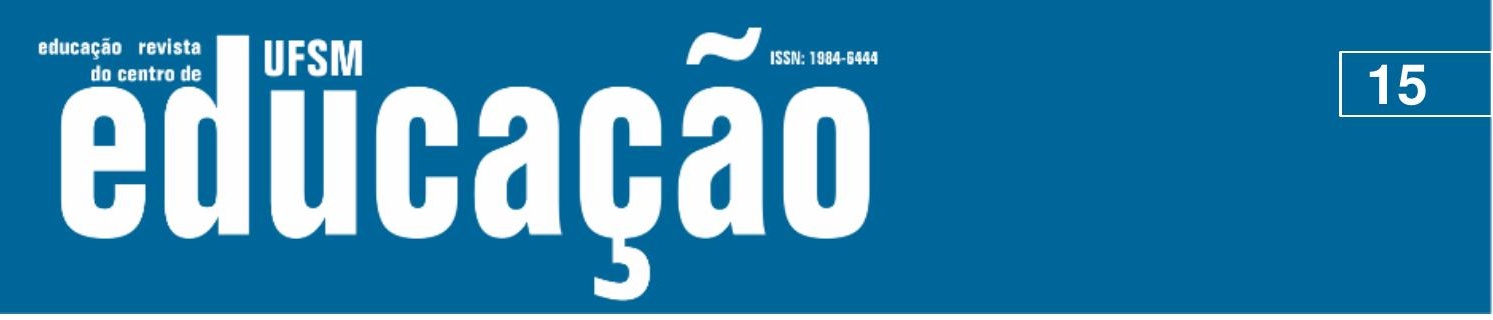

ISSN: 1984-6444 | http://dx.doi.org/10.5902/1984644442506

$\mathrm{Na}$ escola procuramos fomentar esse tipo de pensamento com experiências mais objetivas, como professor de Geografia. Enquanto o ser humano se pensa geograficamente, tem determinadas capacidades, determinados conhecimentos. O professor é um promotor de conhecimentos e um produtor de conhecimento, mas não se fala isso, não se tem atribuído aos professores [referindo-se aos professores da educação básica], apenas aos professores da academia. Se valoriza muito mais os pesquisadores, mas os professores de Geografia [da escola] também possuem a capacidade de construir conhecimento geográfico.

Como se pode observar a partir das compreensões oriundas de cada professor participante, existem distintos aspectos que, relacionados, constituem o pensamento geográfico sistematizado ao longo do tempo no que se define como ciência geográfica. Da mesma forma, existe um emaranhado de elementos que convergem para a construção de um modo de pensamento específico dos professores de Geografia e que se constitui na ciência geográfica, na sua dimensão pedagógica e no conjunto de conhecimentos e saberes inerente à escola.

Os aspectos que emergem das falas constituem dados importantes para a discussão proposta, apresentados, a seguir, na forma de categorias construídas por meio da Análise de Conteúdo (BARDIN, 2011), interpretados sob o olhar da Teoria Crítica e da Hermenêutica.

\section{Interpretações sobre pensamento geográfico e pensamento geográfico de professor}

Nas interpretações, as categorias emergem da estrutura de pensamento demonstrado pelos professores, o que tornou possível identificar diferentes dimensões necessárias à sua constituição. As categorias elencadas são: a) Dimensões profissionais (a ciência geográfica; a identificação de si e da ciência); b) Dimensões formativas subjetivas/pessoais (a construção acadêmica; o conhecimento de senso comum); c) Dimensões sociais e o contexto (a realidade/cotidiano; o contexto).

a) Dimensões profissionais: essa categoria abarca elementos que influenciam na construção de conhecimentos a partir da formação acadêmica inicial. 


\title{
Uism

ISSN: 1984-6444 | http://dx.doi.org/10.5902/1984644442506

fragilidades e distanciamentos entre o modo de pensar e o modo de abordar geográfico. Essa fragilidade aparece em determinados momentos, quando a relação entre a dimensão teórico-conceitual, específica da Geografia, não está devidamente articulada à dimensão didático-pedagógica, esta que se relaciona à forma como o professor conduz a ação docente e as abordagens que pretende desenvolver.

Sobre como compreendem o pensamento geográfico, os professores mencionam a ciência base - a Geografia - como um dos elementos, além de uma construção acadêmica aliada a uma dimensão de saber comum, relacionado ao cotidiano e ao contexto. Eles possibilitam também pensar estas relações que precisam construir na caminhada da docência, perpassando pela dimensão profissional, social e subjetiva, que constitui sua identidade de professor.

Tais elementos convergem na construção da identidade docente. A perspectiva de identidade aqui defendida se embasa nas reflexões de Habermas (1990), ao considerar que a identidade do Eu se constitui por meio da linguagem. Nesse sentido, conforme Angelico (2015, p. 9):

\begin{abstract}
A identidade dos indivíduos socializados constitui-se ao mesmo tempo por intermédio do entendimento linguístico com os outros, bem como por intermédio do entendimento intrasubjetivo. Em suas interações comunicativas, os atores podem desenvolver suas identidades por meio da troca argumentativa que realizam uns com os outros. O sujeito se desenvolve e se autocompreende a partir de reconhecimentos recíprocos por meio dos quais os indivíduos definem as suas identidades.
\end{abstract}

Considerando a identidade de professor de Geografia procura-se tecer reflexões sobre a existência de um Pensamento Pedagógico-Geográfico de Professor (PPG), que sustenta essa identidade haja vista que, de acordo com Souza, Souza e Carneiro (2021), a construção da identidade docente também constitui um processo de desenvolvimento indissociável da identidade pessoal, que perpassa estágios na própria trajetória escolar ao campo de atuação, recorrente da intersubjetividade e reafirmação da docência. 


\section{A constituição de um Pensamento Pedagógico-Geográfico de Professor e a autonomia docente}

A defesa é de que deva ser construído um modo de pensamento articulando a especificidade da Geografia científica e a dimensão escolar, pois constituem o profissional professor de Geografia. Nesse sentido, compreende-se que construir-se professor remete a uma dimensão teórico-metodológica e epistemológica, mas, também, envolve a dimensão pedagógica e as subjetividades que são, também, aspectos necessários ao processo de educar.

Os conhecimentos geográficos e pedagógicos constituem no professor algo que não é apenas um pensamento geográfico de professor, mas um modo de pensar peculiar, denominado Pensamento Pedagógico-Geográfico que, além de sustentar um modo de pensar geograficamente se refere a um modo de abordar geograficamente (COPATTI, 2019).

O Pensamento Pedagógico-Geográfico de professor (PPG) possibilita refletir sobre o modo como se constitui professor e como ensina Geografia, sobre que estruturas manipula mentalmente, como complexifica seu pensar a partir de elementos basilares à docência que, em interação, sob um processo contextualizado, (res)significado e, desde a argumentação, têm novos sentidos e constituem, também, novos conhecimentos.

Compreende-se que existem processos internos e processos externos que contribuem para a formação de um modo de pensamento de professor de Geografia. Existem especificidades do conhecimento científico e escolar, que constituem a base para a formação e a atuação do professor. Existem também outros conhecimentos implicados nesse processo e, ainda, um conjunto de aspectos da dimensão social e das subjetividades que confluem na trajetória de vida de cada professor, a partir de suas experiências, e que interferem na construção desse pensamento.

A consciência da existência de fatores externos e internos que envolvem a mobilização de processos mentais, de ações e intenções contribui para que se 


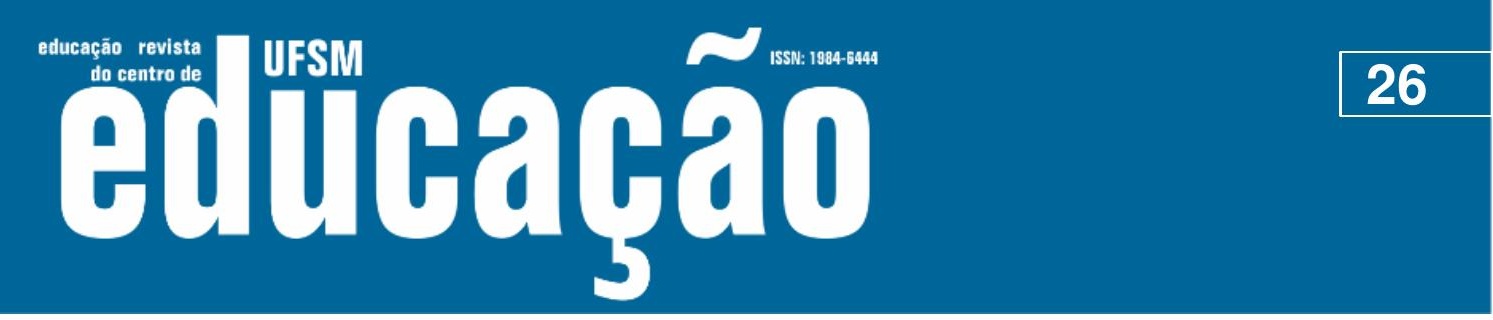

ISSN: 1984-6444 | http://dx.doi.org/10.5902/1984644442506

clarificação de como realizar interpretações geográficas e resolver problemas do mundo da vida sob o olhar geográfico; possibilita o entendimento sobre quais elementos toma como basilares à argumentação que desenvolve, à problematização que propõe. Contribui, ainda, para que este profissional construa, gradativamente, sua autonomia docente, compreendida não somente como a liberdade para atuar em sala de aula, mas tendo claros os elementos a serem tomados como basilares à construção da sua professoralidade e que constituem parte da sua identidade docente.

\section{Referências}

ANGELICO, Gabriela G. A linguagem como identidade emancipatória em sociedades multiculturais: desafios e possibilidades a partir de Jürgen Habermas. XIII Semana de Relações Internacionais - UNESP. 2015. Disponível em: https://www.marilia.unesp.br/Home/Eventos/2015/xiiisemanaderelacoesinternacionai s/a-linguagem-como-identidade_gabriela-garcia.pdf. Acesso em 20 jul., 2021.

BARDIN, Laurence. Análise de conteúdo. Tradução Luís Antero Reto e Augusto Pinheiro. São Paulo: Edições 70, 2011.

BRITTO, Luiz Percival L. Livro didático e autonomia docente. Scripta, Belo Horizonte, v. 6, n. 11, p. 162-170, ํㅗ sem. 2002.

CALLAI, Helena C. A formação do profissional da Geografia: o professor. ljuí, RS: Editora Unijuí, 2013.

CASTELLAR, Sonia M. Vanzela. Educação geográfica: a psicogenética e o conhecimento escolar. Cad. Cedes, Campinas, vol. 25, n. 66, p. 209-225, maio/ago, 2005.

COPATTI, Carina. Pensamento pedagógico geográfico e autonomia docente na relação com o livro didático: percursos para a educação geográfica. Tese (Doutorado em Educação nas Ciências). Programa de Pós-Graduação em Educação nas Ciências. UNIJUI, 2019.

CONTRERAS, José. Autonomia de professores. São Paulo: Cortez, 2002.

GOMES, Paulo C. da Costa. Quadros geográficos: uma forma de ver, uma forma de pensar. Rio de Janeiro: Bertrand Brasil, 2017. 


\section{Altharẫ \\ 3}

ISSN: 1984-6444 | http://dx.doi.org/10.5902/1984644442506

KUHN, Martin. O professor: identidade e protagonismo - os muitos modos de dizer o ser e o fazer do professor e de se dizer. Tese (Doutorado em educação) Universidade Regional do Noroeste do Estado do Rio Grande do Sul, 2016.

MARCELO GARCÍA, Carlos. A formação de professores: novas perspectivas baseadas na investigação sobre o pensamento do professor. In: NÓVOA, António (org.). Os professores e a sua formação. Lisboa: Dom Quixote, 1992.

MARQUES, Mario Osorio. A formação do profissional da educação. 5. ed. Brasília: Editora Inep, 2006. (Coleção Mario Osorio Marques).

MORAES, Antônio C. Robert de. História do pensamento geográfico no Brasil: indicações. Geografares, Vitória, n. 3, jun. 2002.

MOREIRA, Ruy. O que é Geografia. São Paulo. Editoração: Coletivo Território Livre, 2009.

SOUZA. Anny C. N. de. SOUZA, Sérgio D. G. de. CARNEIRO, Rosalvo N. Identidade docente em Geografia e programas formativos: uma interpretação Habermasiana. Geog Ens Pesq, Santa Maria, v. 25, e10, 2021, pp. 1-38.

STEIN, Ernildo. Crítica da ideologia e racionalidade. Porto Alegre: Movimento, 1986.

STURZA, José A. I. Lugar e não-lugar em Rondonópolis-MT: um estudo de cognição ambiental. 2005. 163 p. Tese (Doutorado em Geografia). Universidade Estadual Paulista, Rio Claro. 2005.

SUERTEGARAY, Dirce M. A. Notas sobre epistemologia da Geografia. Cadernos Geográficos, Florianópolis, n. 12, maio 2005.

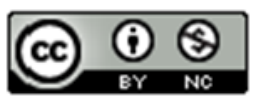

This work is licensed under a Creative Commons Attribution-NonCommercial 4.0 International (CC BY-NC 4.0) 